\title{
MÁS ALLÁ DEL TIEMPO Y DEL ESPACIO: LA SOLIDARIDAD COMO PILAR SECULAR Y TRANSNACIONAL DE LA REPRODUCCIÓN FAMILIAR Y SOCIAL SONINKÉ
}

\author{
Beyond time and space: Solidarity like \\ secular and transnational spindle of \\ Soninké's family and social reproduction
}

Berta Mendiguren*

\begin{abstract}
RESUMEN
La sociedad soninké ha logrado perdurar en el tiempo y el espacio a pesar de haberse convertido la migración en un fenómeno estructural. En situación transnacional, la reproducción del orden social tradicional, fundamentado en el patrilinaje y atravesado de múltiples desigualdades (entre clases sociales, generaciones y géneros), es posibilitado por la actualización de las diferentes redes de solidaridad y compromiso mutuo, que tanto familiares como comunitarias, la caracterizan. Y que se traducen tanto a través de las remesas como del asociacionismo. Sin embargo, el creciente cierre de fronteras que se vive en Europa así como la situación de las segundas y terceras generaciones nacidas en exilio estaría poniendo en peligro a la sociedad soninké en su conjunto.
\end{abstract}

Palabras-clave: soninké; solidaridad; migración transnacional.

\begin{abstract}
Soninké society has managed to last in time and space in spite of migration which has turned into a structural phenomenon. In transnational situation, the social reproduction of a traditional order, based on the patrilinaje and crossed of multiple inequalities (among social classes, generations and gender), is possible by the update of

* Investigadora-Consultora Internacional Independiente. Dra. en Antropología de la Salud, Máster en Cooperación Internacional y Diplomada en Trabajo social. Tfno: 00.34.94.463.63.93. E-mail:
\end{abstract} mendigurenberta@yahoo.es. 
different solidarity networks and mutual commitment, that characterizes this society as familiar as much as communitarian. And that is translated through economics aid and associationism. Nevertheless, increasing border's closing, such as in Europe, as well as the situation of the second and third generations born in diaspora would be putting in danger soninke society as a whole.

Keywords: soninké; solidarity; transnational migration.

\section{Introduccion}

El presente artículo aborda una de las ideas clave de la investigación-acción ${ }^{1}$ que entre enero de 1999 y junio de $2004^{2}$ desarrollamos entre las poblaciones migrantes subsaharianas de mayor tradición migratoria hacia Europa, las de etnia soninké 3 y sus comunidades de origen en África: de cómo las diferentes redes de solidaridad y compromiso mutuo, tanto familiares como comunitarias, que caracterizan la sociedad soninké, se perpetúan en el tiempo y el espacio incluso en situación transnacional constituyendo unos de los pilares seculares de su reproducción social.

Previo a su abordaje resulta necesario señalar cómo uno de los elementos claves en la correcta comprensión de dicho fenómeno ha resultado ser la estrategia metodológica empleada. Una metodología cualitativa, que acorde con la perspectiva holística y relacional de la Antropología ${ }^{4}$, nos llevó a desplazarnos entre Malí y Europa, entre al ámbito rural (poblados de Dramané y Makhanás ) y el urbano (Kayes, Bamako y París), simulando

1 Esta ha dado lugar a la tesis doctoral titulada Inmigración, medicalización y cambio social entre los soninké: el caso de Dramané (Malí), la cual obtuvo el Premio Extraordinario de Doctorado 20062007 de la Universidad Rovira i Virgili de Tarragona (España).

2 Dicha investigación es igualmente fruto de una nutrida experiencia como trabajadora social con inmigrantes sub-saharianos iniciada en España en 1992, continuada en Francia desde 1996 y retomada en España a la vuelta de Mali en julio de 2004.

3 En la bibliografía en español se utiliza el término saraholé, aún cuando en francés se use el de soninké. Optaremos por éste último al ser con el que autodenominan los miembros de dicha comunidad.

$4 \mathrm{Y}$ en especial de la subdisciplina denominada Antropología de la Salud ya que nuestra tesis ha tenido como sujeto de estudio cómo dichas comunidades se valen del proceso de medicalización para gestionar el cambio social derivado de las migraciones.

5 Nuestra investigación se centró en el área sanitaria de Dramané, poblado soninké de 3.766 habitantes según el ultimo censo que data de 2001 . Situado a $70 \mathrm{~km}$ al oeste de Kayes y equidistante de 30 $\mathrm{km}$ de la frontera senegalesa y mauritana, Dramané pertenece al mismo área sanitaria que los 3 poblados soninké de Makhadougou, Makhalagaré y Toubaboukané conocidos como los 3 Makhaná. 
las rutas migratorias de sus miembros. Y en la que fueron protagonistas la población soninké y sus parientes migrantes, gracias a la preeminencia de técnicas como la observación participante complementada con entrevistas, historias de vida y genealogías ${ }^{6}$ así como por el análisis histórico y bibliográfico.

Su análisis ha de aportarnos elementos de conocimiento, reflexión e intervención sobre el rol y estrategias de mantenimiento a través del tiempo y el espacio de las redes de solidaridad existentes en el África subsahariana gracias al ejemplo de esta etnia que la comunidad científica internacional estima ser la que simboliza, al menos en Europa, "más fuertemente las migraciones de mano de obra provenientes del sur del Sáhara"7. Sin embargo, la correcta comprensión de dichas redes de solidaridad y compromiso mutuo encuentra un sentido y una lógica que si previamente son contextualizadas en la milenaria historia y organización social de este pueblo migrante.

\section{Los soninke, un pueblo migrante y milenario}

Según la tradición histórica ${ }^{8}$, la etnia soninké, proveniente del Mediterráneo, fundó hacia el año 300 d.c. la primera entidad política de la Región del Alto Senegal-Níger: el Imperio de Wagadu o Ghana. Su capital se situaba en Koumbi-Saleh (actual Mauritania), extendiéndose del Océano Atlántico hasta Tombuctú (Mapa I). Su principal fuente de riqueza era el comercio trans-sahariano, sirviendo de alto en el camino de las caravanas que transitaban entre África del Norte y el centro del continente africano. Los bereberes con el fin de acapararse de sus riquezas comienzan su persecución en el s.VIII y en 1076, la armada almorávide ocupa la capital y los principados dependientes de Wagadu que pasan a constituirse como pequeños reinos independientes. Posteriormente los bereberes almorávides

6 Se residió en concesiones soninké durante 2 años y medio, entrevistando en múltiples ocasiones a un total de 233 actores sociales.

7 BAROU, J. Les soninké d'hier á demain. Revue Hommes \& Migrations, p. 9-12, 1990.

8 Para un magnífico estudio de su historia: BATHILY, A. Les portes de l'or: le royaume de Galam (Sénégal) de l'ère musulmane au temps des négriers (VIIIe-XVIIIe siècles). L'Harmattan, 1989. 
deciden aliarse con el Imperio naciente de Malí y en 1240 el Imperio de Wagadu cae definitivamente en sus manos. Sus poblaciones, organizadas por clanes y linajes, deciden emigrar hacia el sur (incluida la zona aquí en estudio), mezclándose con otros pueblos y fundando en algunos casos "reinos autónomos como es el caso del Gajaaga, Gidimaxa y más al este, en el Mali actual, los reinos de Jafunu, Mema, Kingi y Giyune". De ahí que desde el s. XI los soninké ocupen una banda de unos $800 \mathrm{~km}$ "entre Matam (Senegal) y Sokolo (Malí)"'10.

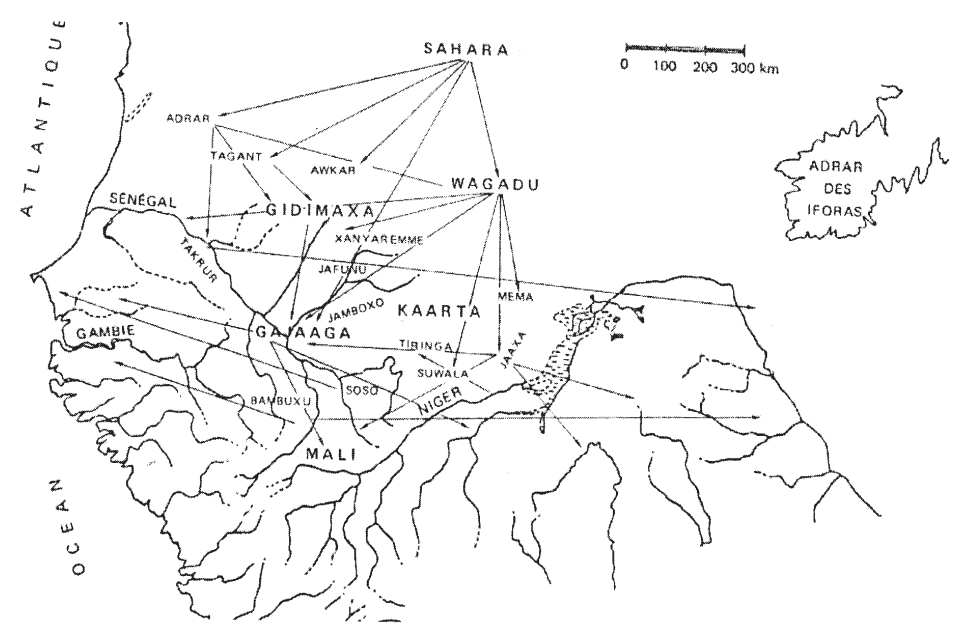

MAPA 1 - Zonas de asentamiento soninké entre principios del I milemario y el año 1500 d.c. (BATHILY, A., loc. cit., p. 126).

Uno de sus principales asentamientos coincide con los límites de la actual región de Kayes, al Oeste de Malí, en donde se sitúan los poblados de Dramané y Makhaná (Makhadougou, Makhalagaré y Toubaboukané), locus principal de nuestra investigación (Mapa 2).

Los 3 poblados que componen Makhaná son la sede del poder político del citado reino de Gajaaga o Gadiaga ostentado por el clan guer-

9 BAROU, J. Loc. cit., p. 10.

10 FAINZANG, S.; JOURNET, O. La femme de mon mari. Anthropologie du mariage polygamique en Afrique et en France. L'Harmattan, p. 16, 1988. 


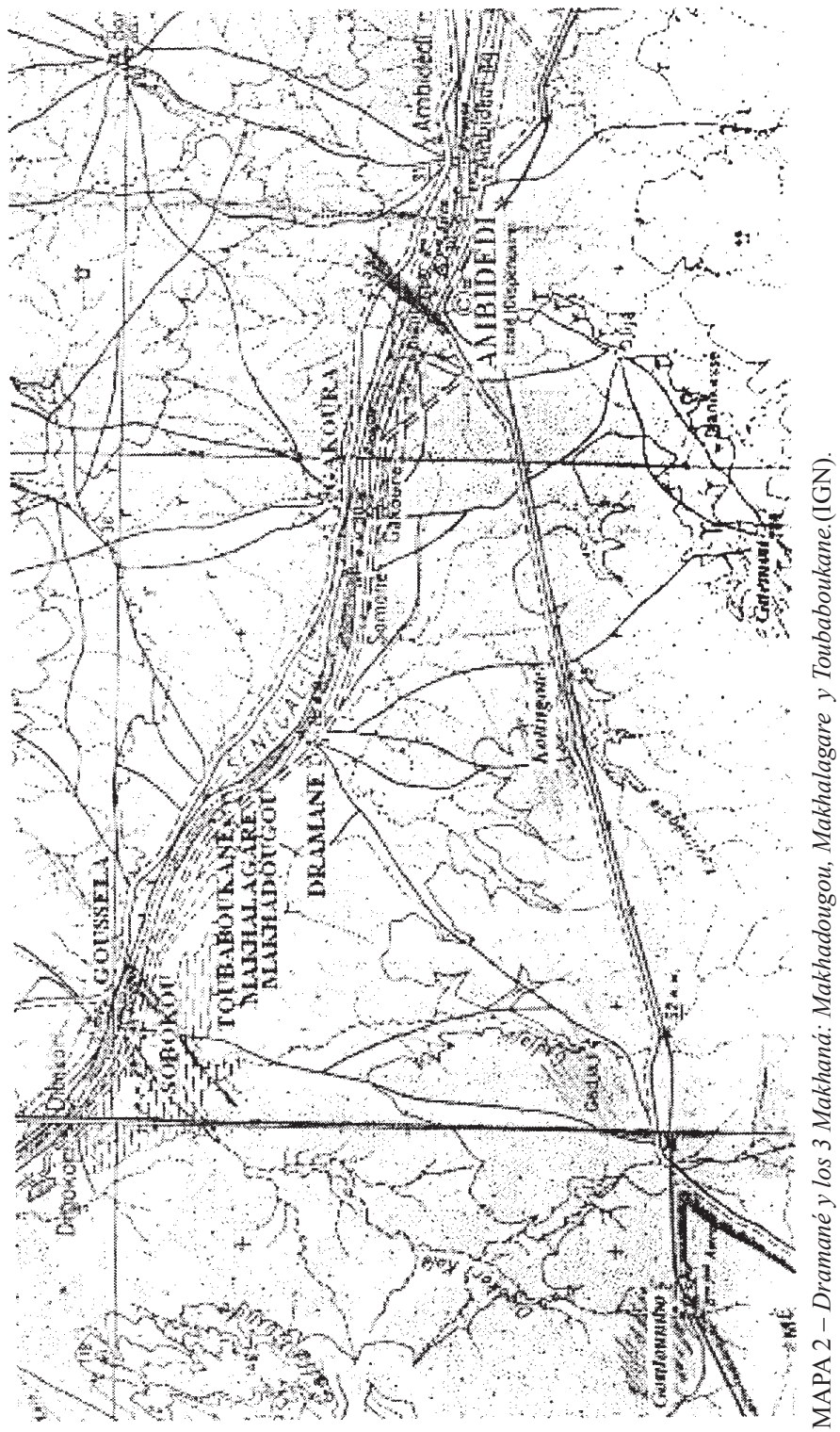


rero "Sempera-Bathily que dirigirá el país desde fines del siglo VIII"11. Posteriormente llegó a la zona el clan de marabúes Dramé Kandjí que se instaló en los terrenos ofrecidos por el clan Bathily al este de su capital y que actualmente constituyen el poblado de Dramané. Según Bathily “basándonos en la historia general del Gadiaga, la emergencia de esta ciudad (Dramané) se sitúa entre finales de s. XIII y principios del s. XIV"12.

Y es así que desde su creación los poblados del área en estudio han constituido un lugar estratégico a nivel geográfico y comercial habiendo determinado su emplazamiento el rol capital que jugaron en los inicios de la penetración comercial y militar de los franceses en el antiguo Sudán francés $^{13}$. Sin embargo la economía soninké basada tradicionalmente en la agricultura y el comercio (de oro, goma arábica y esclavos) acabó siendo marginalizada por la empresa colonial que apartó a esta región de los circuitos que anteriormente dominaba, viniendo a su vez a empobrecer a las familias nobles la emancipación de los esclavos decretada en 1905 por la metrópoli. De este modo los clanes nobles tuvieron que ponerse a trabajar en la agricultura y a buscar en la emigración un complemento, actividad que acabaría siendo desde el último tercio del s. XX el pilar de su economía. La historia nos muestra "cómo ya desde el s. XIX hay asentamientos de esta etnia en África Central y sin que ello corresponda a una situación económica catastrófica" ${ }^{\prime 4}$. En efecto y desde finales de dicho siglo las migraciones soninké toman nuevos rumbos, dirigiéndose en especial hacia Senegal (plantaciones de cacahuetes situadas a lo largo del eje Dakar-Saint-Louis y Dakar-Kayes) y sin olvidar el resto del continente, de modo que en la actualidad existen importantes comunidades soninké desde Sudáfrica hasta Libia, Costa de Marfil o Guinea Conakry.

El éxodo hacia Europa comienza durante la Primera Guerra Mundial, cuando la potencia colonizadora (Francia) aprovecha la familiaridad de los soninkés con la navegación para embarcarlos como mecánicos en

11 BATHILY, A. Loc. cit., p. 11.

12 BATHILY, A. Loc. cit., p. 115.

13 Las fuentes históricas señalan que el 1 de septiembre de 1698, Brue, director de la Compañía francesa de Senegal, llegó a Dramané "localidad poblada por comerciantes soninké que profesan el Islam como el rey de Gadiaga”. DELAFOSSE, M. Haut-Sénégal-Niger: Le pays, les peuples, les langues. Maisonneuve, p. 384, 1912. Brue fundó en el mismo año en Makhalagaré el primer fuerte construido por los franceses en el antiguo Sudán.

14 DAUM, C. Les associations de Maliens en France. Migration, développement et citoyenneté. Karthala, p. 93, 1998. 
la marina de guerra. Al final de la misma, miembros de esta etnia llegan a las costas francesas instalándose en Marsella, Burdeos o Le Havre. Ya en 1919 los archivos de Yelimané (Kayes) señalan cómo "las operaciones de reclutamiento han permitido constatar que en ciertos poblados están ausentes alrededor del $70 \%$ de los jóvenes inscritos como aptos para el servicio militar" 15 . Actualmente la casi totalidad de los poblados al borde del río Senegal han visto gran parte de sus hombres jóvenes migrara, variando su porcentaje según las fuentes, aunque podemos situar "la media de inmigrantes en el 54\% de la población total de los poblados"16. Desde la década de los 70' constituyen la mayoría de los sub-saharianos instalados en Francia, aunque desde los 90' aparecen nuevos destinos como Italia, EEUU o España. En el caso de nuestra investigación, el primer inmigrante del área de Dramané llega a Francia en los 40'. La primera mujer en 1973 por reagrupación familiar. El flujo continua a pesar de las restrictivas políticas migratorias europeas.

En definitiva, los procesos migratorios se han convertido en un fenómeno estructural que como veremos afecta a los pilares mismos de esta sociedad. Como dice un proverbio soninké Dalla gumme ya mpasu Kalle $n g a$, es decir Vale más trabajar en el extranjero que morir en su casa ${ }^{17}$.

\section{El patrilinaje, pilar historico de la sociedad soninké}

Las fuentes históricas y antropológicas ${ }^{18}$ confirman el testimonio de nuestros interlocutores: "si hemos conseguido perdurar a través de los siglos es gracias a que somos uno sólo, una gran familia y entre todos nos ayudamos" (E.H. Bathily, noble, rey de Gadiaga). En efecto, y desde la Antigüedad, los soninké se han organizado en base a clanes y linajes, siendo la familia extensa patrilineal la base de dicha organización y pilar de su reproducción junto a la solidaridad (Figura I).

15 DELAFOSSE, M. Loc. cit., p. 16.

16 DAUM, C. Contribution des immigrés au développement de leur pays: le cas des Maliens de France. OCDE, p. 85, 1995.

17 BAROU, J. Loc. cit., p. 11.

18 Ver el ya citado Bathily, A. o POLLET, E.; WINTER, G. La société Soninké (Dyafunu, Malí). Université Libre, 1971. 
FIGURA I - ESTRUCTURA DE LA ETNIA SONINKÉ

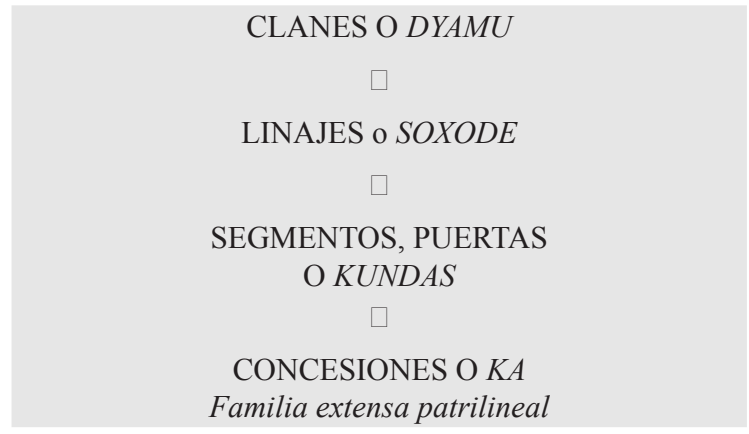

Es así que en cada poblado la mayoría de la población pertenece al clan fundador (Bathily y Dramé Kandjí en el caso Makhaná y Dramané respectivamente) al que han venido a unirse posteriormente clanes o linajes extranjeros. Los clanes identificados por su apellido (dyamu) se dividen en linajes (soxodé) y estos, al aumentar sus miembros ${ }^{19}$, en segmentos denominados "puertas" (kundas). Cada linaje(o en su caso cada segmento) pasa a ocupar una (o varias) concesiones ( $\mathrm{ka}$ ) en la cual reside cada familia extensa patrilineal. A su vez los poblados al crecer pueden subdividirse en barrios (kudas). Un claro ejemplo lo tenemos en Dramané (Figura II).

El patrilinaje es denominado en soninké kille, que significa "el camino". La familia extensa patrilineal se encuentra constituida por el más anciano y jefe de la familia (kagumé), sus esposas, sus hermanos cadetes y sus cónyuges así como del conjunto de sus descendientes sobre 2 o 3 generaciones. Todos los miembros de una misma familia extensa patrilineal cohabitan en una misma concesión $(\mathrm{ka})$ que constituye de facto una unidad de residencia, producción, consumo y reproducción. La talla de cada concesión varía entre medio urbano y rural llegando en el caso de los poblados de nuestra investigación a alcanzar hasta 300 personas conviviendo en un mismo $\mathrm{ka}$.

La regla de residencia matrimonial es patrivirilocal. El matrimonio preferencial es el que se realiza entre primos y especialmente entre primos entre hermanos.

19 Puede darse igualmente el caso de que un linaje se segmente por problemas de autoridad 

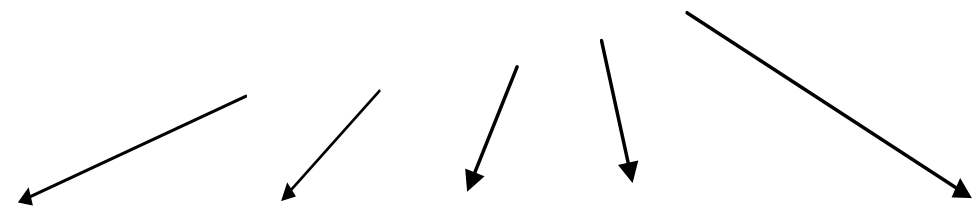

CLAN FUNDADOR: DRAMÉ KANDJÍ

\begin{tabular}{|c|c|c|c|c|}
\hline SOUMAILO & WALI & SIRE & KOMONGALOU & TAMBODOUGA \\
\hline \multicolumn{4}{|c|}{ (hijos de Dramé Kandjí) } & (linajes llegados con posterioridad) \\
\hline \multicolumn{4}{|c|}{ Linajes Dramé fundadores por orden de llegada } \\
\hline $\begin{array}{c}\text { SOUMAILO- } \\
\text { SOXODÉ }\end{array}$ & $\begin{array}{c}\text { WALI- } \\
\text { SOXODÉ }\end{array}$ & SIRE-SOXODÉ & KOMONGALOU & TAMBODOUGA \\
\hline HORONGALOU & \multicolumn{3}{|c|}{ WALISOXODE } \\
\hline \multicolumn{4}{|c|}{ Localización geográfica de los linajes en barrios o Koudas ${ }^{20}$} \\
En cada barrio: Kundas y Kas
\end{tabular}

paralelos patrilineares. También ocupa un lugar privilegiado el matrimonio en el interior de la concesión, el linaje, el clan o en el seno del poblado. Intercambios regulares de esposos tienen lugar entre linajes rivales desde la fundación de Dramané y Makhaná lo cual permite gestionar antagonismos. La poliginia en esta sociedad fuertemente islamizada es altamente apreciada al haber sido recomendada en la surata IV, 2 del Corán. Las mujeres, en caso de no estar casadas en el interior del $K a$, lo abandonan yendo a vivir al del marido. A la muerte de éste, la mujer continúa bajo la dependencia del nuevo jefe de familia e incluso puede ser casada con el hermano de su marido, siendo frecuente el levirato.

Respecto a la filiación, en esta sociedad la descendencia pertenece al patrilinaje y el tener hijos se considera la principal función de la mujer, jugando los parientes del lado materno un rol más afectivo y solidario. Reglas de residencia, alianza y filiación que son una de las múltiples expresiones de la situación subalterna en la que se encuentra la mujer en esta sociedad.

$\mathrm{Al}$ interior de la concesión existe una clara jerarquización dada por la edad, la cual opera por orden de nacimiento y pertenencia a una generación. El jefe de la concesión (kagumé), se encuentra en la cima de la

20 Dramané, al ser un poblado de gran talla se compone de 2 barrios: Soumailosoxodé y Sire soxodé. 
pirámide social. Tiene derechos y poder sin necesidad de ser competente. Los cadetes tienen obligaciones sin derecho a la palabra ni a la toma de decisiones. Estos aún casados le deben sumisión y "poseen una autonomía económica parcial" "21. A menudo, el Kagumé demasiado anciano delega una parte del espacio decisional a un hermano cadete o al mayor de sus hijos.

Pero, el sujeto soninké no sólo forma parte de un hogar, de una familia extensa, de un linaje y de un clan, sino que se encuentra inmerso en otras redes de pertenencia que conforman su identidad y a cuya reproducción social como veremos contribuye igualmente la solidaridad: la clase social, los grupos de edad, la pertenencia a un mismo barrio ver a un mismo poblado.

Es así que en esta sociedad fuertemente jerarquizada, el patrilinaje determina igualmente el status social del individuo (Figura III). La posición social depende en primer lugar de la condición de hombre libre o esclavo, siendo el ya citado apellido (diamou), en definitiva el clan de pertenencia, quien señala la pertenencia a una u otra clase social y ello desde el nacimiento. El diamou nos habla del origen libre o esclavo y con ello del lugar social del individuo, de sus derechos y obligaciones respecto a los miembros de su clan y respecto a los otros clanes ${ }^{22}$.

\section{FIGURA III - ORGANIZACIÓN SOCIAL SONINKÉ}

\begin{tabular}{|c|c|c|}
\hline \multirow{8}{*}{$\begin{array}{l}\text { - Clanes de } \\
\text { hombres } \\
\text { libres: }\end{array}$} & \multirow{4}{*}{ Nobles o Hoore: } & $\begin{array}{l}\text { - con mando: tunka (reyes), debegumé (jefes de } \\
\text { poblado) o koudagumé (jefe de barrio). }\end{array}$ \\
\hline & & - mangé (jueces) \\
\hline & & - hankaman (guerreros) \\
\hline & & - imanes y marabúes (religiosos) \\
\hline & \multirow{4}{*}{ Artesanos o Nyakhamala: } & - gesere o tradicionalistas. \\
\hline & & - dyare o griots. \\
\hline & & - tage o herreros-joyeros. \\
\hline & & - garanké o zapateros. \\
\hline \multicolumn{2}{|c|}{ - Clanes de esclavos: } & $\begin{array}{l}\text { - komé o esclavos de trata adquiridos por el } \\
\text { comercio y que pueden ser vendidos. }\end{array}$ \\
\hline
\end{tabular}

21 LAVIGNE, P. La rizière et la valise. Irrigation, migration et stratégies paysannes dans la vallée du fleuve Sénégal. Syros Alternative, p. 26, 1991.

22 Esta jerarquización define igualmente el campo de alianzas matrimoniales posible estando prohibido el matrimonio entre libres y esclavos, e incluso al interior de una misma clase social. Así en Dramané está prohibido entre una mujer de un clan marabútico y un hombre Bathily "pues perdería la buena práctica de la religión ya que los Bathily no son buenos musulmanes” (A. Tirera, noble). 
Entre los hombres libres hay que distinguir dos castas: la de los clanes nobles (hoore) y los de casta o artesanos (nyakhamalas). Entre los nobles existen a su vez los clanes que detentan el poder político (en manos de los reyes, de los jefes de cada poblado y de cada barrio), los encargados de la distribución de justicia (mangue) con un rol de tesoreros, los que poseen el poder religioso (imán y marabúes), así como los guerreros (hankaman). Cada linaje fundador tiene asociado una serie de linajes guerreros con los que conforma una entidad denominada kabila. Por ejemplo el linaje Dramé-Kandji fundador del barrio de Dramané denominado Soumailosoxodé (Figura II), tiene asociado 3 linajes guerreros: Kanouté, Tirera y Yatabaré. Cada clase social tiene una manera de ser y hacer (dambe) que debe ser respetada y actualizada en toda relación social ${ }^{23}$. Ser noble supone orgullo, endogamia, poder de decisión así como ser prolijo en dones sino se humilla al patrilinaje.

Los artesanos u hombres de casta (nyakhamalas) mantienen la antigua especialización del trabajo: los tradicionalistas (gesere), los griots (dyare), los herreros-joyeros (tage), y los zapateros (garanké). Las mujeres ejercen la misma actividad que su marido o una actividad relacionada ${ }^{24}$. Antiguamente estaban ligados a un linaje noble que les mantenía y para el cual trabajaban, en la actualidad suelen constituir concesiones independientes. Su manera de ser, no sometida a "la obligación del orgullo" les permite ser indiscretos y pedigüeños.

Respecto a los esclavos (komé), se trata de los descendientes de los antiguos esclavos de guerra. A pesar de la abolición de la esclavitud decretada por Francia en 1905, el término esclavo sigue designando a una clase social que continúa sometida a las obligaciones propias del rango heredado de sus antepasados con respecto del linaje noble al que pertenecía su familia. Cada familia de esclavos continúa llamando a su maestro por el nombre de kamanugo o kamanagaré.

Además la sociedad se encuentra organizada en grupos de edad. Se trata de jóvenes que han hecho la infancia juntos formando una sociedad

23 POLLET, E.; WINTER, G. Loc. cit., p. 227.

24 Así, las mujeres de los herreros pueden ser ceramistas o dedicarse a la realización de la escisión, la mujer del zapatero realizar tatuajes o ser peluquera. La introducción de artículos manufacturados ha desplazado la actividad artesanal. Así, por ejemplo, el herrero no produce más que algunas joyas y mantiene el material agrícola aunque su rol subsiste en las ceremonias de matrimonio, bautismo o defunción. Así por ejemplo el ritual del matrimonio es ejecutado por los clanes artesanos de las familias en unión. Son ellos quienes van y vienen entre las dos familias con el fin de establecer los términos de la alianza. 
jerarquizada. El jefe será el niño que, perteneciente al linaje que ostente el poder en el poblado, tenga mayor edad. Cada barrio (kouda) o en su caso poblado tiene su grupo de edad tanto masculino como femenino. Es así que los rituales de la circuncisión ${ }^{25}$ y de la toma del pantalón ${ }^{26}$ se celebran por grupos de edad. A menudo residen en una choza separada de sus concesiones de origen aunque sigan bajo la autoridad de su kagumé.

Los barrios, en caso de existir, conforman un nuevo nivel de pertenencia, identidad y organización social. Es así que por ejemplo, previa a una reunión del poblado, cada barrio de Dramané se reúne separadamente para discutir los asuntos que le conciernen más directamente. Asimismo algunos servicios se prestan por barrios como queda patente en la organización de una cooperativa de alimentos ${ }^{27}$ en cada barrio de dicho poblado. Sin embargo, y a pesar de dichas subdivisiones, podemos afirmar la continuidad de un sentimiento común de pertenencia a un mismo poblado, especialmente patente frente a los poblados vecinos: "Makhaná, los Bathily, son los reyes, pero el poder de Dramané es el religioso, y Allah es más fuerte que todo" (E. H. Dramé, noble).

En definitiva, la organización social soninké así como su estructura y normas muestran claramente como el individualismo es raro. Cada soninké no tiene sentido más que a través de su pertenencia a múltiples redes: la etnia, el clan, el linaje, la familia, la clase social, el grupo de edad, el poblado, el barrio, el reino, la religión. Como dice un proverbio soninké Baanakhum da Allah baane ya nafa, es decir La soledad no es buena más que para Dios. Y ello a través de los siglos e incluso en exilio.

25 El principal rito de iniciación masculina es la circuncisión. Tradicionalmente, tiene lugar hacia los 12 o 13 años (un año antes de la "toma del pantalón”) y es realizada por la casta de los herreros. En el caso de las niñas, el ritual paralelo es la ablación del clítoris que se realiza durante los días que siguen al nacimiento y no da lugar a rituales públicos.

26 La toma del pantalón simboliza el abandono de la infancia de los miembros de sexo masculino. A partir de ese momento, hacia los 14-20 años, el joven es considerado adulto. En dicho ritual los jóvenes de un mismo grupo de edad visten por primera vez un boubou (túnica) grande y un pantalón largo. Su paralelo para las niñas es el fendeli o toma del paño.

27 Se trata de estructuras comunitarias para la compra en común de víveres al exterior del poblado de modo que puedan ser puestos a la venta en el poblado a un precio inferior que si fueran adquiridos de modo individual. 


\section{Nuevos espacios y reproduccion social soninke}

Una vez asentados en el extranjero, los soninké tratan de reproducir su comunidad de origen, es así que "todos los observadores se han sorprendido por la fuerza de la tendencia a reconstituir las estructuras comunitarias inspirándose de los modelos de la sociedad de origen" ${ }^{\text {28. }}$. En el caso del destino preferente de los protagonistas de nuestra investigación, Francia, el hecho de residir de modo colectivo en residencias ${ }^{29}$ contribuye igualmente al mantenimiento de dicha organización, pues éstas pueden ser consideradas como poblados-bis. Su impacto es importante ya que en dicho país se calcula que "el $71 \%$ de inmigrantes malienses viven en residencia" ${ }^{30}$. Todo esto no es ajeno a Dramané y Makhaná, cuyos inmigrantes residían, en el momento de realizar nuestra investigación, concentrados en 6 residencias parisinas con un total de 335 familias dependientes ${ }^{31}$. Este hecho contribuye efectivamente a la reproducción del orden social pues "entre los que provenimos del Gadiaga, la tradición pesa mucho, pero sobre todo en Dramané que son marabúes muy poderosos, que tienen poderes y por ello posibilidades de hacer daño... En las residencias nos organizamos como en el poblado y eso no permite que cambiemos las mentalidades" (E.H. Cissoko, esclavo).

Es así que en la diáspora, los soninké tratan de reproducir el orden social gracias al mantenimiento de la lógica productiva, de consumo y residencia del patrilinaje así como de las normas de alianza y filiación ${ }^{32}$.

28 BAROU, J. Loc. cit., p. 11.

29 Residencias destinadas a albergar los inmigrantes provenientes de las colonias, sin pareja y de sexo masculino, creados a partir de 1948 por el gobierno francés. Los ocupados por los trabajadores africanos del valle del Senegal recrean la vida del poblado con sus artesanos, comerciantes, sala de oración, organización por poblado y familia, consejo de ancianos.

30 QUIMINAL, C. Du foyer au village. L'initiative retrouvée. Rev. Hommes \& Migrations, v. 1131 , p. $19,1990$.

31 La mayor parte de ellos residen en las residencias de la calle Bisón-París XX (81), Quai de la Gare-París XIII (71) y Charonne-París XI (64) situadas París intramuros. 103 viven en apartamentos de la región parisina y 11 en Troyes. Tomado del Cuaderno de Cotizaciones del año 2003 de la Asociación de residentes de Dramané en Francia.

32 El mantenimiento de la endogamia aparece en exilio como una preocupación mayor pues a menudo las segundas generaciones y siguientes no presentan tal preferencia. Además el creciente cierre de fronteras abría dejado como única puerta de entrada legal el matrimonio con lo que se habría encarecido el montante de la dote. Al mismo tiempo habría permitido permitido un mayor desarrollo de la poliginia, pues el dinero ganado permite pagar nuevas dotes. 
Asimismo tratan de perpetuar las desigualdades sociales existentes en origen (por clase social, edad, y/o género): “en París, los Traorés continúan siendo los esclavos de los Tirera. Por ejemplo, son ellos quienes se encargan de la acompañar a las novias Tirera durante los días que siguen a su boda" (A. Tirera, noble).

El sentimiento de pertenencia a un mismo clan, a un mismo poblado es igualmente mantenido. Un ejemplo de ello lo constituyen episodios como el ocurrido en el 2002 en un suburbio de París, cuando un noble de Dramané pasó una noche "de ronda" con un fusil en mano a la puerta del apartamento de una mujer del poblado (ante la estupefacción de sus convecinos) pues ésta era pretendida por otro soninké de un poblado cercano, obligado a defender el honor de su patrilinaje y de su pueblo pues dicha mujer había estado casada con un miembro de su familia extensa.

\section{La solidaridad, el otro pilar de la reproduccion social soninké}

En el seno de la sociedad maliense, los soninké aparecen como el grupo étnico "que lleva más allá el sentido de la ayuda mutua y la solidaridad"33. Solidaridad que es vivida tradicionalmente como una obligación fundamentada en la ideología del parentesco así como en la religión musulmana predominante en la zona en estudio ${ }^{34}$ ya que "la ley coránica habría dicho que si tienes algo no puedes dar la espalda a tu familia. Así que tengo obligaciones, todo el mundo me señala a mí. Son mis parientes [...] También con cualquier musulmán aunque no le conozca" (B. Yatabaré, noble).

33 N’DIAYE, R. Kayes et le Haut Sénégal: La ville de Kayes. Tome II. Populaires, p. 11, 1972.

34 Como ya hemos señalado Dramané ostenta el poder religioso en el seno del reino de Gadiaga cuyo mayor símbolo es el hecho de que su mezquita de los viernes sirva como punto de referencia de todos los poblados al borde el río Senegal en un radio de $30 \mathrm{~km}$ Construida en 1972 en el centro neurálgico del poblado, fue ésta la primera realización colectiva de los inmigrantes. La religión musulmana es asimismo enseñada en Dramané. En casi cada concesión hay una escuela coránica (medersa) las cuales cuentan con una gran reputación en la región. Además existe una escuela franco-árabe compuesta de seis clases. Ciertos marabúes tienen gran renombre y reciben consultas de toda la región debido a sus conocimientos en materia religiosa y a sus supuestos poderes ocultos. 
Ideología solidaria que rige múltiples aspectos. De un lado, organiza las reglas de producción y consumo al interior de cada concesión garantizando de este modo la subsistencia de todos los miembros del patrilinaje y con ello su reproducción social: "Somos de la misma familia, eso supone que cultivamos el mismo campo, tenemos la misma fuente para comer, trabajamos todos para el mismo granero, somos todos uno y todos nos debemos al Kagumé" (A. Tirera, noble). Los impuestos son igualmente asumidos a nivel de cada concesión. De otro, los gastos en ropa, educación o de asistencia en caso de enfermedad, son asumidos por el adulto de sexo masculino que sea el jefe de cada uno de los hogares que componen el $k a$, quién en caso de no poder hacer frente a dichos gastos, podrá recurrir al kagumé el cual regenta y dispone según su criterio del fondo común de la concesión. Si a su vez éste no puede asumir dichos gastos podrá recurrir a otros Kagumés de la misma puerta, del mismo linaje, o en su caso del mismo clan. Asimismo la ideología del parentesco es actualizada a la hora de participar solidariamente con los gastos derivados de los diferentes rituales que conforman la sociedad soninké: fiestas, bautizos, bodas, entierros.

Solidaridad que como vemos garantiza no sólo la supervivencia sino también la reproducción del status quo soninké, y que tiene igualmente una clara relación con la ideología del género. Es así que mientras los hombres están obligados a ser solidarios con toda persona que se encuentra en situación de inferioridad, ya sea por ser más joven y/o por tener menos medios, y en especial con toda mujer y/o menor que no tenga un hombre que la/lo tome a cargo, las mujeres no están obligadas a ello, siendo en su caso la solidaridad una opción libre:

Si la persona tiene medios, no. Por ejemplo mi hermana Haby. Ella está casada, vive aquí en París y trabaja, tiene su capital propio a ella. Si no, sí que estoy obligado, sobre todo con los del lado de mi madre [...]. Además el Corán lo dice, ayudar a la viuda, al huérfano.... Se trata no sólo de un vínculo con los de tu concesión, con los de tu kunda, no. Los soninkés, por todas partes aparece nuestro deseo de mantener los lazos familiares, los de solidaridad, es en realidad lo mismo, familia es solidaridad. Sobre todo entre la gente de Dramané es muy importante...entre los de Makhaná también. Todos somos una familia. Luego, cuando se es familia, es muy importante mantener los vínculos. Y un modo es ayudando. Tú no estás sólo 
y no eres nadie sólo [...] En cambio nuestras mujeres, no, no tienen porqué ayudar, si lo hacen es porque quieren, y quieras o no en ese aspecto se ven privilegiadas. Si obtienen algo de dinero, lo pueden guardar para ellas (M., Yatabaré, noble).

Asimismo y en clara relación con la ideología del parentesco, así como con la estructura social y derivados de la historia de instalación en el poblado, existen lazos especiales al interior de los clanes nobles que se traducen en una serie de obligaciones, incluidas la de realizar dones. Según J. Bathily, hijo del jefe del poblado de Toubaboukané: "Los Bathily damos media recolección a los Dramé. Los Dramé si alguno fallece nos dan un montón de carne, concretamente la pata derecha del animal. Esto es así desde que los Dramé llegaron aquí hace cientos de años".

Mientras, los clanes y linajes de hombres libres de casta (nyakhamalas) no están sometidos a la presión del dambe, de ese saber ser y estar de los nobles, "pudiendo ser indiscretos, pedigüeños e interesados" ${ }^{35}$. Es así que durante nuestra presencia en el área en estudio asistimos en varias ocasiones a la petición, ver exigencia, de determinados bienes por parte de miembros del linaje de casta adscrito al patrilinaje noble de los Yatabaré en cuya concesión residíamos. Peticiones de diferente carácter: un televisor, una cantidad de dinero o unos medicamentos ante la cual el Kagumé Yatabaré no pudo negarse ya que "es así y siempre ha sido así, hay que darles lo que pidan, aunque ellos tengan más que tu". Ahora bien, en el caso de los clanes de esclavos, sus obligaciones respecto a su maestro (kamanugo o kamanagaré) persisten en la actualidad no sólo en los momentos ceremoniales sino también en la prestación de trabajos. Así por ejemplo es el esclavo quien sirve agua a la llegada de un huésped a la concesión de su kamanugo.

A nivel de los grupos de edad, los lazos de hermandad se actualizan en los procesos de ayuda mutua o en las ceremonias. Un ejemplo de ello es el hecho de que para muchos de los jóvenes que llegan como inmigrantes a Europa, su viaje ha sido cofinanciado por los miembros de su grupo de edad ya presentes en el país de acogida en colaboración con los migrantes de su ka, e incluso de su linaje.

Sin embargo el principio de solidaridad encuentra su límite cuando el beneficiario adquiere riqueza y puede competir en prestigio y poder

35 FAINZANG, S.; JOURNET, O. Loc. cit., p. 20. 
con el dador. Se es solidario si el otro está en situación de penuria, si no la rivalidad, y la envidia se instalan, incluso al interior de las familias (entre hermanos, coesposas), familias, barrios, pueblos, regiones. Ahora bien, dicho límite no aplica en determinadas ocasiones. Es el ya citado caso de la solidaridad al interior de la estructura social (los clanes nobles no pueden no ser "solidarios" con los de artesanos y/o esclavos aún cuando estos cuenten con una situación económica mejor). $\mathrm{O}$ el caso de la realización de trabajos comunes. Así por ejemplo si se desata un fuego, se convoca a todos los jóvenes del poblado, lo cual ocurre igualmente a la hora de sentar las fundaciones de una casa en cemento, y ello independientemente del grado de riqueza de sus participantes.

Otra de las manifestaciones de la solidaridad en el seno de esta sociedad, que actualizada a nivel de cada concesión, no se rige por dichos límites es la hospitalidad con la persona de paso por el poblado o ciudad de residencia, incluso si ésta no pertenece a ninguna de las ya citadas múltiples redes sociales de los miembros de la concesión de acogida. Expresión solidaria que recibe la denominación de costumbre del primer anfitrión o djatigia. Para un soninké, independientemente de su lugar de residencia, es un deber moral acoger a la persona que esté de paso. A su vez, el reconocimiento de los favores recibidos obliga a un individuo a no cambiar de anfitrión en sus desplazamientos, aún cuando éste carezca de medios para acogerlo o un pariente más próximo se instale en el lugar. Dicha figura merece un gran respeto, asegurando un proverbio soninké que: "Más vale evitar un lugar si no vas a quedarte en casa del primero que te recibió en él". Todos los poblados soninké de nuestra zona de estudio poseen uno o varios anfitriones en Bamako y a veces en Kayes, Dakar e incluso París, Brazzaville o Nueva York. Se trata normalmente de un funcionario, comerciante, artesano o migrante que se ha instalado en el ámbito urbano y que sirve de punto de encuentro entre la ciudad y el poblado, cumpliendo múltiples funciones sociales que podemos asimilar a la previsión social: lugar de acogida de los enfermos del poblado, de los inmigrantes en vacaciones, y en el caso de Bamako y Dakar de los jóvenes que esperan su oportunidad para poder migrar. Estancia que puede prolongarse años, asumiendo el anfitrión las gastos derivados, aun cuando la persona acogida pueda (sin estar obligada) contribuir a sufragar los mismos.

Paralelamente encontramos en el seno de la sociedad soninké expresiones modernas de la solidaridad como la existencia de asociaciones 
al interior de cada poblado. Es el caso de la cooperativa de cada uno de los 3 Makhaná o las existentes en cada barrio de Dramané. Asimismo citar la asociación creada por las mujeres de Dramané que desde 1995 se han organizado, gracias a la financiación de la Banca Africana de Desarrollo (BAD), bajo la denominación, Asociación Leer y escribir en soninké ( $O$ na xaran na safa ${ }^{36}$. Su objetivo: el desarrollo integral del poblado a través de la alfabetización funcional en soninké y del apoyo a la creación de actividades económicas y de horticultura. Desde 1999 cuentan con un perímetro irrigado comunitario que persigue la mejora del equilibrio alimenticio así como favorecer la autonomía financiera de las mujeres.

La cara opuesta y más sombría a dicha obligación de ser solidarios, de compartir en familia ver en comunidad, lo tenemos en la posibilidad de no ser solidario con aquel miembro que haya osado alterar el orden social, lo cual denota el rol clave que juega el mantenimiento del orden social para la reproducción de los soninké. Y ello incluso en el caso de correr peligro la vida del "infractor". Es así que durante nuestra investigación tuvimos que "combatir" contra dicha norma en el caso de un noble del linaje fundador de Dramané, enfermo de cáncer, que precisaba de una evacuación sanitaria a Europa a cuya financiación solidaria se negaron en un principio sus parientes, a excepción de su mujer y su suegro. La razón: en su juventud había osado aprender el oficio de herrero, propio de los clanes de casta, por lo que su clan en castigo había procedido a su "muerte social". Tras muchas trabas "sociales" se logró reunir el dinero necesario para su evacuación.

A su vez la solidaridad en sus diversas expresiones, tanto individual, familiar como colectiva, tradicional o moderna, no sólo actuaría de sistema de cohesión y de protección social (a pesar de sus "excepciones") sino que tendría otras funciones "menos solidarias". Es así que en esta sociedad profundamente jerarquizada la solidaridad serviría al mismo tiempo para reforzar el poder y el prestigio ${ }^{37}$ de quien da en la línea de lo señalado por Meillassoux ${ }^{38}$ según el cual "el que da adquiere una imagen revalorizante,

36 Esta asociación contaba en el 2004 con 370 miembros de los cuales $300(81,08 \%)$ son mujeres.

37 Búsqueda de poder y prestigio que a su vez alimenta la migración "existiendo un consenso tácito entre inmigrantes y kagumés para que el dinero ganado en inmigración (...) sea convertido, al menos en parte, en prestigio social" (LAVIGNE, P. Loc. cit., p. 35). Así los soninké derivan una gran parte de los recursos adquiridos en el extranjero en gastos ostenta torios (ganado y joyas por ejemplo) realizando raramente inversiones a nivel productivo o en ahorro.

38 MEILlASSOUX, C. Terrains et théories. Anthropos, p. 156, 1977. 
donde se mezclan generosidad y éxito, siendo la capacidad de redistribuir una manifestación del poder: dar no es signo de generosidad necesariamente, sino sobretodo la activación social de los bienes que actúan como medios de reproducción social".

En todo caso y como bien nos decía uno de nuestros interlocutores: "Si tú no puedes hacer la carrera sólo más vale que le enseñes a correr al otro, así haréis la carrera juntos. Y para ello tiene que estar en buen estado de salud, alimentado [...] ¿ves? Hay que ayudarse. Por eso hay que guardar los lazos familiares, siempre, siempre" (A. Tirera, noble).

\section{Otros espacios, viejos y nuevos rostros de la solidaridad soninké}

De nuevo y aun cuando la situación transnacional, suponga un gran reto para el mantenimiento del orden ${ }^{39}$ y los valores soninké, la solidaridad "resiste", contribuyendo a la reproducción social e incluso posibilitando el éxodo. Como bien nos decía uno de nuestros interlocutores, él mismo migrante en París desde hace varias décadas: "nuestro verdadero valor es la solidaridad. Tu eres es la hija del hermano pequeño de... y te dejo sufrir, sólo porque estas lejos, porque estás en Dramané, o qué sé yo en Abidjan... pero si tu buscas encuentras que aunque lejano, siempre hay entre nosotros un parentesco, y no, no te dejaré sufrir. Haré todo por ayudarte" (A. Tirera, noble).

De un lado y como bien expresa el proverbio soninké Morir o Burdeos, la tradición obliga a todo joven adulto a migrar en caso de ser elegido como candidato adecuado por su familia ${ }^{40}$. En contrapartida todo

39 Contrariamente a lo señalado por BAROU, J. (loc. cit., p. 11), nuestra investigación vino a mostrar como entre los soninké, la inmigración sí es vivida "como un peligro de explosión de la comunidad de origen o como un riesgo de pérdida de las raíces".

40 En varias ocasiones y diferentes concesiones asistimos al proceso de selección de un joven como candidato a la migración. Esta se realiza no en base al deseo del candidato sino de los criterios del jefe de cada ka, de los hombres adultos casados de la misma y de los migrantes de la concesión asentados en el extranjero. Sus cualidades: ser un joven sumiso, respetuoso del orden y la moral tradicional, solidario con su familia y fuerte físicamente. 
candidato a migrante se compromete a "dejar su familia en el poblado que con la intención de ayudarla"41. Es así que el proyecto migratorio de los hombres soninké tendría como objetivo principal el ser solidarios con la realidad de limitado desarrollo humano en la que viven sus parientes. Por su parte la finalidad de dicha solidaridad se situaría de nuevo en posibilitar la reproducción social ${ }^{42}$ soninké en un contexto transnacional actuando asimismo como un sistema de protección social:

Ayudas a que sobrevivan, cuando se ponen enfermos, la ropa, la educación, las bodas... Pero al mismo tiempo de lo que se trata es de asegurar la permanencia del lazo con el poblado respondiendo a las peticiones de los parientes. Es uno de los modos de mantener la unión con ellos. Si los rompes: ¿Qué te queda? ¿Quién eres? ¿Para qué has venido hasta aquí? Pierdes tu identidad y es el fin tuyo y de los demás [...] ¿En los soninkés el principio de todo es el lazo familiar. Es eso lo primero en los soninké, es lo que nos ha mantenido a través de los siglos (A. Tirera, noble).

Y todo ello sin olvidar la búsqueda de poder y prestigio social:

Entrando en el juego de la ostentación, los inmigrantes han mantenido el mito de la emigración. A través de los envíos y regalos, han creado una reacción de dependencia. Ciertos inmigrantes de vacaciones son obligados a pedir un crédito para continuar a responder a las solicitaciones de todo tipo. Al mismo tiempo no pueden negarse a ser solidarios sin verse con la familia o el poblado contra ellos ${ }^{43}$.

Hechos todos ellos que han llamado especialmente la atención de agentes de desarrollo e investigadores: "La solidaridad y el sentido de la organización de los soninké en el extranjero es remarcable [...] En cualquier medio en el cual se integren, se observa que los soninké se reagrupan

41 QUIMINAL, C. et al. Les nouveaux comportements dans la crise. Mire, p.10, 1987.

42 Junto al mantenimiento de la solidaridad, del sistema de alianza y filiación así como de la religión musulmana, los soninké encuentran en el mantenimiento de la lengua soninké en exilio otra estrategia privilegiada de reproducción social.

43 LAVIGNE, P. Loc. cit., p.:32. 
rápidamente en estructuras modernas como cooperativas o asociaciones. La autoayuda, la solidaridad en la emulación he aquí valores que se encuentran a menudo en las comunidades soninké" 44 . Y ello especialmente entre los clanes nobles: "En París, en Bamako, se siguen tejiendo lazos de solidaridad eventuales...lo cual es especialmente presente entre los miembros de los linajes nobles a quienes el rol de jefes de poblado les es asignado" ${ }^{45}$. Como bien confirmara uno de nuestros interlocutores: "Sí, es importante el hecho de que soy del linaje fundador de Dramané. Quizás hasta más que para alguien de una familia de casta o esclava. Y ayudando, tú sólo o a través de la asociación, refuerzas esos lazos, sigues siendo uno, y siendo el jefe" (S. Dramé, noble).

Más allá de sus finalidades y de su carácter obligatorio, la solidaridad de los migrantes soninké se concretiza a diversos niveles. De un lado, tratan de dar respuesta a las necesidades básicas de su patrilinaje (alimento, vivienda, vestido, salud, educación, gastos rituales etc...) a través de las remesas. Los beneficiarios de su solidaridad serán en primer lugar los miembros de su $\mathrm{ka}$. En caso de residir al exterior varios miembros de una misma concesión los envíos son conjuntos, aun cuando en caso de estar casados, paralelamente y de modo individual, cada migrante pueda enviar una cantidad complementaria directamente a su esposa (o a la primera de ellas en caso de tener varias). Tras ayudar a su concesión, el migrante deberá ayudar a los miembros de su segmento de linaje (kunda) y en especial a los parientes del lado materno ${ }^{46}$. Asimismo deberá solidarizarse con la suerte de las familias que han contribuido al pago de su viaje, incluidos los miembros de su grupo de edad. Los inmigrantes entrevistados lo corroboran y subrayan el rol jugado por la poligamia: "Los primeros a ayudar son los de tu concesión. Con tus tías y tus hermanas no tienes obligación. Bueno si están casadas con gente sin medios... Si ves que su marido prefiere ocuparse de su otra esposa, ayudas. Si no, ayudas indirectamente a través de la asociación" (M. T. Sawané).

44 SISSOKO, B. Les bouchers de Bamako. Une catégorie ethnoprofesionelles bien spécifique. En Colectivo (Eds.). On ne ramasse pas une pierre avec un seul doigt. Organisations sociales au Mali: un atout pour la décentralisation. Bamako: Fondation Charles Léopold Mayer, p. 98, 1996.

45 DAUM, C. Loc. cit., p. 67.

46 Como lo prueba un proverbio soninké que dice que "si cortas la barba, sale sangre, pero si cortas los senos, sale leche". 
Ya en 1991 Catherine Quiminal señalaba como el salario de los migrantes soninké puede ser dividido en tres rúbricas: el dinero de la dependencia (es decir el enviado a sus parientes en origen), el de la autonomía (para sufragar sus gastos en Francia) y el ahorro de precaución (inversión personal y/o familiar así como el destinado a las asociaciones). Todo ello se traduce en que en 1996, el dinero de la dependencia representaría el $31 \%{ }^{47}$ del dinero ahorrado por los inmigrantes ${ }^{48}$. Estos envíos, recibidos y gestionados por el kagumé, permitirían en el poblado "cubrir entre el $40 \mathrm{y}$ $50 \%$ de las necesidades de víveres"49, constituyendo "entre el 30-70\% del presupuesto familiar" ${ }^{\circ 0}$. En el 2004, la Federación Francesa de Cajas de Crédito estimaba en 120.000.000 de euros par año el volumen de dinero enviado desde Francia por los migrantes malienses (en su mayoría soninké) $)^{51}$. Como bien señalaba otro de nuestros interlocutores: "El que viene a Francia, viene para trabajar, para enviar dinero al poblado, responder a las necesidades de su familia extensa. [...] Nadie ha venido para estudiar, o para sí mismo, nadie. Eso es inconcebible" (M. Yatabaré, noble). Asimismo los inmigrantes se responsabilizan de sus familiares recién llegados a Francia, mientras no encuentren un trabajo o están en paro. Roles que los propios migrantes comparan de nuevo con los de un Sistema de Protección Social: "Si uno se pone enfermo, enviamos inmediatamente dinero [...] Hacemos lo que hace el Estado aquí" (M. Bathily, noble).

Respecto a la rúbrica dedicada al ahorro de precaución señalar cómo gran parte se dedica al asociacionismo, aunque son cada vez más numerosos los migrantes que han podido construir en la capital (Bamako) o en la ciudad más cercana a su poblado de origen (Kayes) "para cuando seamos viejos. Además después de tantos años es muy difícil para nosotros

47 Para un salario medio de referencia de $6.000 \mathrm{ff}$ equivalentes a 909 euros.

48 BLION, R.; VERRIERE, V. Épargne des migrants et outils financiers adaptés. Pratiques des immigrés maliens et sénégalais résidant en France. Rev. Migrations-Études, p. 82, 1998.

49 GARNIER, C. Migration, flux monétaires et économie villageoise. Rev. Hommes \& Migrations, v. 1131, p.13, 1990.

50 Debido a ello en los poblados comienzan a aparecer estructuras de ahorro. Anteriormente se trataba de ciertos miembros de la comunidad que ejercían el rol de banco. Así Dramané cuenta con una caja de ahorros y de crédito creada a instancias de la citada asociación de mujeres. Ésta abrió sus puertas el veintiuno de junio de 1999 y está dirigida por un hombre perteneciente al linaje fundador de Dramané: Soumailosoxodé.

51 MILHAUD, C. Étude sur la valorisation de l'épargne des migrants maliens en France. Caisse D'Epargne-Mae, 2004. 
habituarnos al poblado, sin agua, sin luz, con el control social, y la familia que si necesito esto, lo otro..." (A. Cissoko, esclavo)

En lo que se refiere a la forma colectiva de la solidaridad soninké, señalar que en un primer momento los migrantes se organizaron de un modo "tradicional" conformando fondos o cajas comunes de solidaridad (Keesi N'leme) ${ }^{52}$, primeramente regionales que con el aumento del número de originarios de un mismo poblado se convirtieron en cajas de poblado, y posteriormente en asociaciones. Las cajas consisten en un fondo en el que cotizan todos los inmigrantes que trabajan, y que ejerce igualmente de "seguridad social" rente al infortunio, tanto para los parientes en el poblado como para los instalados en el extranjero. Su organización bajo la forma de asociaciones, acogiéndose al régimen jurídico general de asociaciones regido por la ley 1901, data de los años 70' produciéndose una explosión en los 80 '53. Así Daum comenta cómo "la más antigua asociación de inmigrantes soninké malienses en Francia data del año 1973" llegando a afirmar que "alrededor del $71 \%$ de los inmigrantes de cada poblado soninké forman parte de dichas asociaciones" ${ }^{54}$.

Sus actividades se han referido primeramente a la construcción y mantenimiento de las mezquitas de los poblados de origen; tras esto han comenzado a ocuparse de la realización de perímetros irrigados, cooperativas, escuelas y centros de salud. Concretamente en el área en estudio existen 1 caja de solidaridad de Dramané y otra de Makhaná, otras 2 en cada una de los barrios de Dramané así como diversas asociaciones: la Asociación de residentes de Dramané en Francia, la UJOGA - Unión de Jóvenes Originarios de Gadiaga, así como una ASACO - Asociación de Salud Comunitaria conjunta para los 4 poblados. Los migrantes del área de estudio construyeron primeramente la mezquita de los viernes sita en Dramané, tras ello las cooperativas, una escuela franco-árabe y un centro de salud. Abdoulay Tirera nos cuenta cómo ha tenido lugar este proceso:

52 La primera caja soninké en Francia data de 1965 en KANTE, N. 1986.

53 Se da el caso igualmente de la creación de federaciones de asociaciones como IDS-Sahel que, creada en 1992, reagrupa más de 700 asociaciones de inmigrantes del valle del Senegal y cuyo rol es apoyar a éstas en sus relaciones con la administración y otras posibles fuentes de fondos, siendo su proyecto más remarcable la electrificación de la zona. La agrupación se realiza bajo un criterio de pertenencia a una misma zona histórica o a una misma zona administrativa.

54 DAUM, C. Loc. cit., p. 17. 
Cuando llegué éramos pocos y poco a poco nos fuimos organizando. Los primeros de Dramané llegaron en los 40'. En los 60 'vinimos bastantes. Y ahora fijate todos los que somos, más de 400. Todos juntos, como en el poblado. No sólo ayudas a tu familia. Eso lo sigues haciendo pero además ayudamos de modo colectivo a todo el poblado y de modo indirecto tu familia se beneficia. Y el ser asociación nos ayuda a conseguir dinero pues solos es demasiado.

Resulta remarcable como tanto las cajas de solidaridad como las asociaciones respetan la organización social tradicional, actualizando, aunque no sin tensiones, las relaciones de hegemonía y subalternidad existentes entre linajes y clases sociales, ancianos y jóvenes. Así sus representantes son elegidos a mano alzada en base a su posición social:

Todo hombre nacido u oriundo de Dramané, mayor de 18 años, debe inscribirse en la Keesi N'leme. Cada linaje controla que sus miembros que trabajan coticen. Ahora bien, si no trabajas o te jubilas dejas de cotizar. [...] El presidente es siempre un Bathily o un Dramé. Quien lleva el cuaderno de cotizaciones no es un nunca un Dramé. Generalmente somos los Tirera, Yatabaré, los nobles guerreros quienes controlamos. No, el jefe del poblado, no nunca. Uno de casta o un esclavo menos [...] No celebramos elecciones, iqué locura; Hemos funcionado durante siglos así y la migración no va cambiarlo aunque haya algunos a los que el dinero se les haya subido a la cabeza (A. Tirera).

Mientras, las mujeres soninké en exilio actualizan la solidaridad respetando las relaciones de género. Es así que siguen pudiendo beneficiarse del margen de actuación que les permite la norma de la no obligatoriedad de ser solidarias aun cuando su situación en el extranjero les permita en muchos casos disponer de ingresos económicos propios gracias a su acceso a una actividad remunerada. Dicha norma estaría en conformidad con la finalidad de su proyecto migratorio, en cuyo caso la llegada al extranjero es siempre fruto de la reagrupación familiar, que si bien deseada, ha sido decidida por su marido (o su padre), independientemente de la posición social de ambos en la sociedad de origen. Migración cuyo objetivo es el de constituir o reconstruir una familia, asumiendo los roles sexuales y de 
reproducción que la sociedad le asigna tradicionalmente. De todos modos, en caso de trabajar, la mayoría de las mujeres tratan de ayudar a los miembros femeninos de su concesión de origen, y/o de la de su marido, que no cuenten con un inmigrante de sexo masculino que pueda responsabilizarse de sus necesidades: "No venimos aquí por el mismo motivo que los hombres. Ellos vienen para enviar dinero. Nosotras porque nuestro marido está aquí. Esa es la verdadera razón: construir una familia, tener hijos, ocuparnos de nuestro marido. No verás a ninguna mujer soninké que haya venido sin estar casada. Ahora bien, una vez estás aquí y te ocupas de tu marido, de tus hijos, puedes ayudar, pero no estás obligada [...] Nunca, qué locuraj” (K. Dramé, noble). Igualmente es inconcebible que las recién llegadas sean ayudadas por sus hermanas: "Nunca [...] ¿Para que está su marido?” (A. Dramé).

Con el tiempo, y como los hombres, las mujeres han acabado organizando su solidaridad de forma colectiva, aunque las asociaciones femeninas no comienzan a aparecer en Francia más que a partir de 199394. En el caso del área en estudio no fue hasta 1999 que se crearon las 2 únicas cajas de solidaridad femeninas que existen (una por barrio) y que en el 2001 se fusionaron pasando al régimen asociativo bajo la denominación de Asociación de Mujeres de Dramané en Francia a petición de las mujeres del poblado, y en concreto de la ya citada Asociación Leer y escribir en soninké. A pesar de haber contado para su organización con el apoyo de la sociedad de acogida ${ }^{55}$ las normas de pertenencia y gestión reproducen de nuevo el orden social tradicional. Es así que la pertenencia viene dada no por filiación sino por alianza, es decir por el hecho de estar casada con un nativo de Dramané, perdiéndose por divorcio. O que de hecho sean 2 hombres del clan fundador del poblado quienes tomen las decisiones:

No nos hemos organizado hasta hace poco. Antes cada una ayudaba a su familia de su lado. Bueno, seguimos haciéndolo de modo individual pero ahora lo hacemos también de modo colectivo. Son las mujeres del poblado que tienen una asociación antes que nosotras quienes nos han enviado una casete para incitarnos a crear una aquí que reagrupe a todas las mujeres del poblado que viven en Francia en lugar de continuar a cotizar de

55 Concretamente la Ong GRDR les formó en gestión asociativa. Esta ONG se ocupa, tanto en la región parisina como Malí, de proyectos de tipo sanitario, agrícola, hidráulico. En el caso de la Dramané ha formado a sus mujeres a la dirección y gestión. 
modo individual en las dos cajas tradicionales, la del barrio de Horongalou y la de Walisoxodé. [...] Ahora ya tenemos nuestra inscripción. [...] Además ha sido un hombre, Seydou Dramé quien nos ha organizado pues nuestras hermanas de Dramané necesitaban ayuda. Ha llamado a la mujer del más anciano de los Dramé que vive en Francia, es por ello que ella es nuestra presidenta aunque mucho no puede hacer pues es mayor y está muy enferma de los riñones. Su marido es el más viejo, es su mujer quién debe estar delante. Pero quien dirige realmente son dos de sus hijos. Así tiene que ser. Menos mal que hay dos hombres con nosotras. Es necesario que dirijan ellos [...] Los de la ONG GRDR que nos habían ayudado nos dijeron que teníamos que celebrar elecciones y poner a gente joven que sepa leer y escribir pero eso es impensable (K. Dramé, noble).

Su primera realización, a petición de sus parientas en el poblado, ha sido la compra en el mismo año de su constitución de un molino para el huerto. Sin embargo no ha sido hasta agosto del 2008 que la Asociación ha concretizado por segunda vez su ayuda a través de la adquisición y envío de una bomba hidráulica para la irrigación de dicha huerta. Dicha tardanza se ha debido a disensiones internas que actualizan como ocurre en el caso de los hombres, las rivalidades seculares que atraviesan dicha sociedad entre clases sociales, clanes, ancianos y cadetes...

Como los hombres dedican una parte de su ahorro de precaución a la construcción de viviendas en sus países de origen, eso si, nunca en el poblado: "allí son los hombres los que tienen que construir en cemento, que lo hiciera una mujer será impensable" (M. Cissoko, casta).

Las mujeres reconocen igualmente que su solidaridad tiene como finalidad, como en el caso de los hombres, el lograr mantenerse unidas con sus raíces y perpetuar su identidad:

Puedes tener amigos aquí, pero tu sitio está en Dramané, es allí donde tienes tus raíces, tu identidad. Cuando participas en la asociación, cuando ayudas, saben y sabes que sigues unida. Los sabios que ya se han ido han dicho que lo que separa es maldito, que si no te ocupas de los de allí, te maldecirán. La maldición es cuando aquí no te van las cosas bien, y no puedes dormir pensando que estás lejos de Dramané, que no puedes ayudar a una pariente enferma. Queremos seguir unidos. Y 
que la tradición continúe. [...] No sé, es algo que se tiene en la sangre. No sé cómo explicártelo. Los soninké siempre hemos estado dispersos, en exilio, pero siempre hemos estado unidos, hemos ayudado a los del poblado, nos hemos casado entre nosotros, hablamos en soninké, somos musulmanes [...] Los antiguos veían lejos, nosotros no vemos que al lado, y lo que decían es cierto (K. Dramé, noble).

La obligación de ser solidarios de los migrantes soninké sólo finalizará con la jubilación, pasando a ser una opción como en el caso de las mujeres, cambiando como en el poblado al llegar al grupo de edad de los ancianos, los deberes por los derechos como bien explicita A. Tirera: "Yo ahora ya estoy más tranquilo, estoy jubilado. Si continúo ayudando es porque quiero. Es el turno de nuestros hijos". Pero ¿Y si los hijos no quisieran ayudar?...

\section{¿Que futuro para la solidaridad? ¿Que futuro para la sociedad soninké?}

Todos los inmigrantes entrevistados, hombres y mujeres, ancianos y jóvenes, nobles, de casta o esclavos, se preocupan por el futuro de la sociedad soninké en el contexto de la globalización. Dos son los factores clave señalados: el comportamiento de la segunda y tercera generación nacidas e instaladas en Francia así como el creciente endurecimiento de las políticas migratorias en Europa:

Bueno me preocupo ahora que estoy jubilado porque mi hijo no puede responsabilizarse él sólo de toda la concesión. Y además él es un poco toubabou ${ }^{56}$, un poco como los blancos. Pero si un día se le ocurre casarse con una blanca, el ayudar al poblado, no se yo si va a continuar. Así que ahora en nuestra concesión

56 De la palabra árabe "tuba", que significa sabio, nacen las palabras toubib (médico) y toubabou (el blanco). 
lo que nos urge es que otros jóvenes vengan. Otros jóvenes que tengan nuestros valores, que sepan lo importante que es ayudar a los del poblado. Además, si nosotros nos vamos jubilando poco a poco y no hay nuevos jóvenes que vengan y coticen, no sólo ya no podremos ayudar a nuestras familias sino que tampoco podremos enviar dinero de forma colectiva. Porque si estamos esperando a que el estado maliense lo asuma como en Europa...Ahora el problema son nuestros hijos, bueno ya lo hemos hablado antes, es la época de los toubabous. Nosotros decimos vulgarmente toubaboukie, que quiere decir el momento de los blancos y nuestros hijos no buscan los lazos familiares y es por eso que muchos rechazan casarse con uno de Dramané o que no quieren cotizar para el poblado. Incluso si le pides a uno de los jóvenes que ayude te van a decir que no, que ellos tienen que comprarse esto o lo otro, ir de vacaciones...

El miedo ante el futuro es igualmente compartido por las mujeres:

No hay muchos jóvenes nacidos aquí que hagan algo por el poblado. Los que acaban de llegar sí porque de que logran un trabajo van a participar. Pero nuestros hijos nacidos aquí tienen tendencia a que en vez de ayudar se les mantenga a ellos. Tienes que pagarles las vacaciones en la playa, el ir aquí o allí $\mathrm{Y}$ el problema es que ya es muy difícil conseguir un visado, ni con tres o cuatro millones ${ }^{57}$ y nosotros comenzamos a estar viejos [...] Y a los del poblado, no les queda otra para venir que casándose con alguna de nuestras hijas aquí (K. Dramé, noble).

En Makhana y Dramané, nuestros interlocutores confirmaron dichos miedos.

Mientras, la realidad apunta a que las políticas migratorias en Europa van a continuar endureciéndose, por lo que cabe interrogarse sobre el futuro de la sociedad soninké: ¿dónde encontrarán nuevas fuentes de dinero con las que poder ser solidarios, contribuir a la supervivencia de sus parientes y reproducir así el orden social? O quizás como nos dijera el entonces rey de Gadiaga:

57 Equivalentes a 4573.17 y 6097.56 euros respectivamente. 
todo desaparezca, porque nuestros nietos... bueno los que han nacido en Europa han perdido la noción de africanos, y desgraciadamente tampoco son blancos, son mitad, mitad. No conocen el valor de lo que son, de ser soninkés, no conocen el valor de tener parientes [...] Y nuestros antepasados lo dijeron, desapareceremos el día que olvidemos que somos parientes, el día en que no seamos solidarios entre nosotros. Y África va a sufrir por ello (A. Bathily, noble).

Y es que quizás nos encontremos ante un periodo de transición social en cierto modo similar al momento en que Francia decidió abolir la esclavitud, privando a los nobles soninké de su principal fuente de ingresos junto al comercio y a la agricultura. En aquel momento, los soninké encontraron una salida en la inmigración eso si tratando de reproducir en exilio el orden social así como las redes de solidaridad y compromiso mutuo: ¿dónde encontrar una salida ahora? Interrogante sin respuesta. Mientras tanto, continuaremos observando, como Godelier ${ }^{58}$ propusiera para el análisis de los periodos de transición social, "si las modificaciones que provocan son tan sustanciales como para implicar la desaparición de una forma de sociedad", en nuestro caso la soninké.

Recebido em maio de 2009. Aprovado em maio de 2009. de l'Homme, p. 111, 1991. 